\title{
Septal flattening in rest Tc-99m tetrofosmin gated SPECT is a significant predictor of pulmonary hypertension
}

\author{
Salem, Sh.*, El-Shafie, M. ** \\ * Department of Nuclear Medicine, Cairo University, Cairo, Egypt, ** Department of Critical \\ Care, Cairo University, Cairo, Egypt
}

\begin{abstract}
Paradoxical septal motion is commonly described in patients with pulmonary hypertension and right ventricular pressure overload during echocardiographic examinations, but rarely reported during myocardial perfusion studies. Purpose: Our study aimed at documentation of septal flattening during rest gated SPECT imaging with echocardiographic confirmation of pulmonary hypertension or right ventricular overload. Methods: The study included 68 patients [35 males, 33 females], mean age $49 \pm 11$ years with echocardiographic proven pulmonary hypertension. All patients were subjected to conventional echocardiography and rest gated SPECT perfusion scanning following injection of $555 \mathrm{MBq}$ Tc-99m tetrofosmin using triple head general purpose large field scintillation gamma camera.
\end{abstract}

Results: The study population divided into 2 groups; group A: patients showed septal flattening in gated SPECT [56 patients; 82\%] and group $B$ : patients did not show septal flattening [12 patients; 18\%]. Septal flattening in gated SPECT significantly correlated with pulmonary artery pressure $(85.7 \pm 16.4 \mathrm{mmHg}$ for group A

\section{Corresponding Author:}

Shahenda Salem, MD.Associate professor of Nuclear Medicine Cairo University, Cairo, Egypt. Email: afssalem@yahoo.com

Tel: +2 010 1024478; fax: +2 0225257303 compared to $50 \pm 12.5 \mathrm{mmHg}$ for group $\mathrm{B}$, $\mathrm{P}<0.001)$, pulmonary artery diameter $(37 \pm 0.6 \mathrm{~mm}$ for group A compared to $21 \pm 0.4 \mathrm{~mm}$ for group B, $\mathrm{P}<0.02)$, LV diastolic volume $(156.4 \pm 24 \mathrm{ml}$ for group A compared to $111 \pm 12.5 \mathrm{ml}$ for group B, $\mathrm{P}<0.004)$ and $\mathrm{RV}$ tracer uptake. There was no significant correlation between septal flattening and septal thickness $(0.92 \pm 0.16 \mathrm{~cm}$ for group A compared to $0.81 \pm 0.17 \mathrm{~cm}$ for group $\mathrm{B}, \mathrm{P}<0.3$ ) or LV ejection fraction $(60 \pm 6 \%$ for group A compared to $58 \pm 9 \%$ for group $\mathrm{B}, \mathrm{P}<0.2$ ).

Conclusion: Flattening of the interventricular septum [D-shape left ventricle] in gated SPECT imaging correlated with echocardiographic finding of septal flattening and associated with right ventricular overload. The shape of the interventricular septum and the term of septal flattening, if present, should be routinely reported during interpretation of gated SPECT studies similar to echocardiographic descriptions in patients with suspected right ventricular overload.

Key words: Septal flattening, gated SPECT, echocardiography, pulmonary hypertension. 


\section{Introduction}

Myocardial perfusion studies have been extensively utilized to assess patients in the context of coronary artery disease. The classic reporting in this field mentions perfusion abnormalities, motion abnormalities and ejection fraction. Right ventricular [RV] overload assessment by gated SPECT is not a routine indication for myocardial perfusion studies and is not routinely reported. Nevertheless, right ventricle dysfunction has been associated with increased morbidity and mortality in patients with congenital heart disease, valvular disease, coronary artery disease, pulmonary hypertension, and heart failure [1, 2]

Gated SPECT can be utilized to demonstrate right ventricular overload, which was introduced mostly in pediatric population with congenital heart disease, and in adults with pulmonary hypertension $[3,4]$. Increased right ventricular uptake and a peak ratio of right to left ventricular counts over 0.45 have been advocated as a sign of right ventricular overload [3-7].

Furthermore, there are reports about nonspecific perfusion abnormalities in the right ventricle seen in gated SPECT studies in patients with arrhythmogenic right ventricular dysplasia without right ventricular overload [8].

Although patients with pulmonary hypertension and right ventricular pressure overload has demonstrated paradoxical septal motion during echocardiographic examinations $[9,10]$ these were rarely reported during myocardial perfusion studies [11]. This was also applies to interventricular septal flattening which is described and reported commonly during echocardiagraphic examinations of patients with significant right ventricular overload but ignored in gated SPECT perfusion studies.

There are few case reports which mention displacement of interventicular septum toward the left ventricular cavity in patients with right ventricular pressure overload [12]. But still the term interventricular septal flattening has not been utilized in perfusion studies despite similar anatomical counterpart of this phenomenon with echocardiography.

The increase in metabolic uptake in the interventricular septum in FDG-PET scans has been observed in patients with atrial septal defect but again there is no report about occurrence of septal flattening [13].

Our study aimed at documentation of septal flattening during single rest gated SPECT study with echocardiographic confirmation of pulmonary hypertension or right ventricular overload. The correlation between septal flattening and other hemodynamic parameters of the heart can show clinical usefulness in the diagnosis and management of this category of patients.

\section{Material and methods}

The study population included 68 patients with echocardiographic proven pulmonary hypertension and pulmonary artery pressure above $55 \mathrm{mmHg}$ admitted to critical care department, Cairo University in the period from January, 2009 till December, 2010. Patient inclusion and research protocol was approved by the ethical committee. All subjects included in the study had an informed consent before examinations.

All examinee were subjected to full clinical evaluation, resting ECG recording, transthoracic echocardiography and cardiac scintigraphy as follow.

\section{1] Radio-isotopic scanning}

Rest gated SPECT images following injection of $555 \mathrm{MBq}$ technetium labeled tetrofosmin were applied using triple head general purpose large field scintillation gamma camera [MultiSPECT-3, Siemens, USA] 
provided with parallel hole low energy high resolution collimator. Twenty frames

were acquired [30 seconds for each frame] with rotation of 120 degree arc and matrix of $64 \times 64$ and total acquisition time of 12 minutes. Processing and filtering was done using back projection technique and Butterworth filter to get transaxial image, then short axis, vertical long axis, and horizontal long axis cuts. Flattening of the septum was defined as a straight interventricular septum or displacement of the septum towards the left ventricular cavity.

\section{2] Echocardiography:}

Protocol of the study: Each patient was examined according to the American society of echocardiography recommendations. Images from each part of the examination sequence together with standard lead-II of ECG were stored on videotape for subsequent analysis. An ATL-HDI 5000 colored echocardiographic machine was utilized with tissue doppler imaging [TDI] software incorporated in the device using a $3.5 \mathrm{MHz}$ transducer to record: M-mode, 2Dechocardiography and doppler signals in the classic three views: long, short parasternal and apical views.

\section{A) Two dimensional [2D] echocardiogramphy:}

The standard views of the $2 \mathrm{D}$ echo were used in each patient to identify left ventricular contractility, assessment of left ventricular regional function and pulmonary artery diameter [PAd].

\section{B) M-Mode:}

Under guidance of 2D-echo using the parasternal views, the M-mode cursor was positioned at the level of the mitral valve leaflets tips to measure the left ventricular end systolic dimensions [LVESd], left ventricular end diastolic dimensions [LVEDd], left ventricular ejection fraction [EF], interventricular septal thickness diameter [IVSTd].

\section{C) Continuous-doppler trans-tricuspid systolic flow:}

Pulmonary artery systolic pressure [PASP] was assessed using the following formula: $\mathrm{PASP}=4 \times \mathrm{TR}$ peak velocity ${ }^{2}+$ right atrial pressure.

\section{Statistical analysis:}

Data were statistically analyzed using the SPSS 16 Software (SSPS incorporation, Chicago, USA). Quantitative data were summarized and expressed as mean and standard deviation, whereas qualitative data were expressed as frequency. Groups included in the study were compared using the Kruskall-Wallis test and each of the two groups was then compared using the MannWhitney test. Significance was set at the value of less than 0.05 level.

\section{Results}

The study included 68 patients [35 males, 33 females] with mean age $49 \pm 11$ years. Among the study group the diagnosis of pulmonary hypertension was secondary to chronic obstructive pulmonary disease (COPD) [28 patients, $41.2 \%$ ], rheumatic valve disease [20 patients, 29.4\%], systemic lupus erythmatosus (SLE) [8 patients, $11.8 \%$ ], interstitial lung fibrosis [10 patients, 14.7 $\%$ ] and idiopathic in 2 patient [2.9\%]. All patients presented with exertional dyspnea [100\%], while 31 patients presented with exertional chest pain [45.5\%] and 23 patients presented with chest pain at rest [33.8\%].

The study population was divided into two groups: Group A: Patients showing septal flattening in gated SPECT [56 patients presenting $82 \%$ of the study population] (figure 1). 
Group B: Patients not showing septal flattening in gated SPECT $[12$ patients presenting $18 \%$ of the study population].

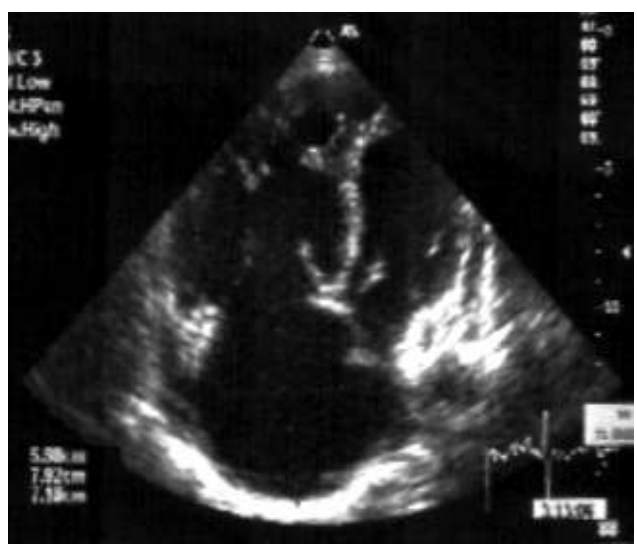

(A)

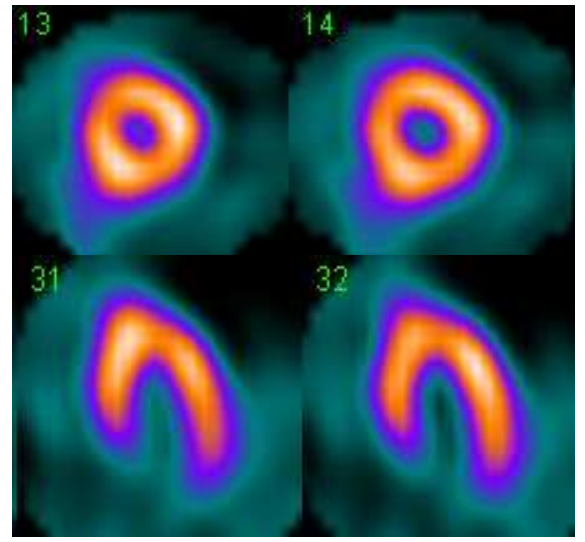

(B)

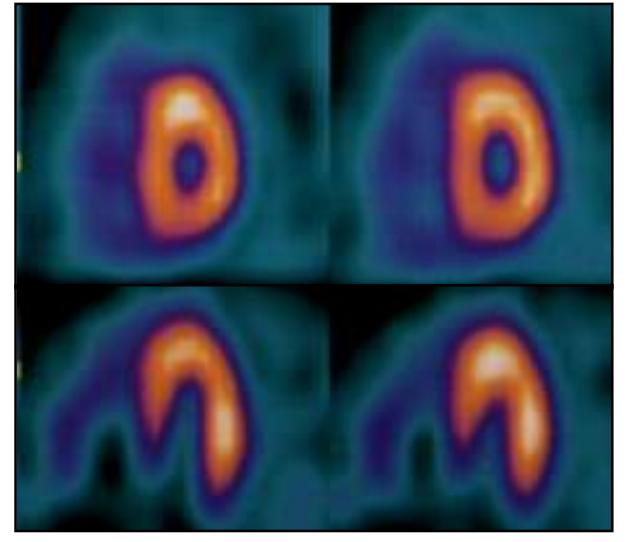

(C)

Figures 1: A patient with pulmonary hypertension: (A) 2D-echocardiography, 4-chambers apical view shows hugely dilated right ventricle and right atrium in pulmonary hypertension with septal flattening. (B) Short axis (upper raw) and horizontal long axis (lower raw) of Tc-99m tetrofosmin rest gated SPECT scan shows septal flattening with increased right ventricular uptake compared to normal rest cardiac scan (C).

\section{Correlation between septal flattening and} pulmonary artery pressure:

Septal flattening was a constant finding in patients with pulmonary artery pressure more than 55 $\mathrm{mmHg}$. The PAP for group A $[85.7 \pm 16.4 \mathrm{mmHg}]$ was statistically significant when compared with that of group $\mathrm{B}[50 \pm 12.5 \mathrm{mmHg}]$ with $P$ value 0.001 .

Correlation between septal flattening and pulmonary artery diameter:

Pulmonary artery diameter in group A $[37 \pm 0.6$ $\mathrm{mm}$ ] was significantly higher than that of group B [2.1 $+0.4 \mathrm{~mm}]$ with $P$ value 0.02 .

\section{.Correlation between septal flattening and left ventricular end diastolic volume:}

The left ventricular end diastolic volume as measured by gated SPECT was significantly higher in group A $[156.4 \pm 24 \mathrm{ml}]$ than in group B [111 \pm $12.5 \mathrm{ml}$ ] with $P$ value 0.004 .
Correlation between septal flattening and left ventricular diastolic function:

Left ventricular diastolic dysfunction as assessed

by echo-doppler [E/A ratio] showed significant difference between group A [1.8 \pm 0.6$]$ and group B $[0.7 \pm 0.3]$ with $P$ value 0.001 .

Correlation between septal flattening and right ventricle/left ventricle $[R V / L V]$ uptake ratio:

$\mathrm{RV} / \mathrm{LV}$ tracer uptake ratio was higher in group A $[0.51 \pm 0.3]$ in comparison to group $\mathrm{B}[0.38 \pm 0.2]$ with $P$ value 0.01 ; denoting right ventricular overload.

Correlation between septal flattening and interventricular thickness:

Thickness of interventricular septum did not show any significant difference between group A $[0.92 \pm 0.16 \mathrm{~cm}]$ and group B $[0.81 \pm 0.17 \mathrm{~cm}]$ with $P$ value 0.3 . 
Correlation between septal flattening and left ventricular ejection fraction:

There was no statistically significant difference in LV EF\% in group A $[60 \pm 6 \%]$ when compared to group B [58+9\%] with $P$ value 0.2 . The scintigraphic and echocardiographic parameters of the two groups with pulmonary hypertension are presented in Table1.

Table 1: Comparison between patients with and without septal flattening

\begin{tabular}{|c|c|c|}
\hline & $\begin{array}{l}\text { Group A } \\
\text { (patients with septal flattening) }\end{array}$ & $\begin{array}{l}\text { Group B } \\
\text { (patients without septal flattening) }\end{array}$ \\
\hline pulmonary artery pressure* $(\mathrm{mmHg})$ & $85.7 \pm 16.4$ & $50 \pm 12.5$ \\
\hline pulmonary artery diameter* (mm) & $3.7 \pm 0.6$ & $2.1 \pm 0.4$ \\
\hline LV end diastolic volume $\$$ (ml) & $156.4 \pm 24$ & $111 \pm 12.5$ \\
\hline LV diastolic function [E/A ratio]* & $1.8 \pm 0.6$ & $0.7 \pm 0.3$ \\
\hline RV/LV uptake ratio & $0.51+0.3$ & $0.38+0.2$ \\
\hline Interventricular thickness* $(\mathrm{cm})$ & $0.92 \pm 0.16$ & $0.81 \pm 0.17$ \\
\hline LV ejection fraction $(\%) \$$ & $60 \pm 6$ & $58 \pm 9$ \\
\hline
\end{tabular}

- assessed by echocardiography, $\$$ assessed by gated SPECT.

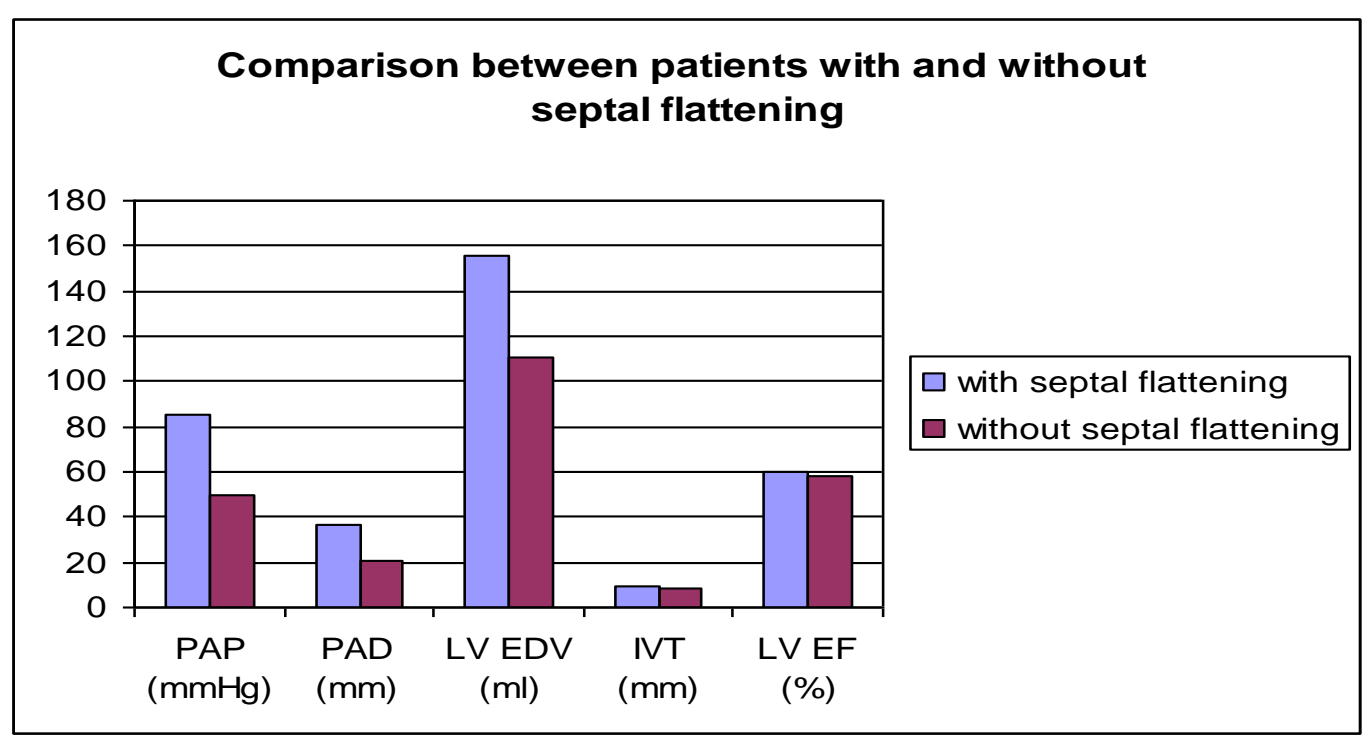

Figure(2): Comparison between patients with and without septal flattening

PAP: pulmonary artery pressure, PAD: pulmonary artery diameter, LV EDV: left ventricular end diastolic volume, IVT: interventricular thickness, LV EF: left ventricular ejection fraction,

\section{Discussion}

Pulmonary hypertension describes a group of progressive increase in pulmonary vascular heterogenous diseases characterized by a resistance, leading to right ventricular failure 
and premature death. The diagnostic approach to pulmonary hypertension, in aspects of imaging and hemodynamic assessment, utilizes

echocardiography, spiral computed tomography and right heart catheterization [14].

Transthoracic echocardiography is the most useful and readily available noninvasive tool to evaluate right ventricular failure due to pulmonary hypertension. Typical findings include right ventricular hypertrophy and dilatation, impaired systolic function and right atrial enlargement. In a cross-sectional view, the left ventricle appears " $D$ " or crescent shaped as the ventricular septum displaces or "flattens" toward the left ventricle [15, 16].

Septal flattening during systole suggests right ventricular pressure overload, whereas septal flattening during diastole occurs with volume overload [e.g tricuspid regurgitation]. Typically in right ventricular failure, septal flattening occurs throughout the cardiac cycle due to both right ventricular pressure and volume overload. The left ventricle contracts normally or is hyperdynamic; however, the diastolic transmitral filling characteristics are abnormal due to reduced left ventricular compliance $[\mathbf{1 5}, \mathbf{1 6}]$

During myocardial perfusion SPECT studies, the right ventricle is often faintly and incompletely visualized. The presence of right ventricular uptake which allows good delineation of the ventricle may be suggestive of right ventricular hypertrophy due to pressure or volume overload [17].

Wackers et al explained that the high tracer uptake in right ventricular wall is related to high right ventricular work load and not just right ventricular hypertrophy. This explains the observation that high tracer uptake in right ventricle did not occur only in patients with right ventricular hypertrophy but in patients with right ventricular overload regardless the cause [18].

Increased right ventricular uptake only seen in stress SPECT images has been described in a patient with severe coronary artery disease. This appears to be related to preserved right ventricular perfusion but reduced left ventricular tracer uptake at stress, thereby resulting in relatively increased right ventricular tracer uptake on stress images [19].

Furthermore, Aepfelbacher et al. showed that among the 52 patients with right ventricular dilatation seen in gated SPECT studies, only 9 patients [17\%] had right ventricular dilatation by echocardiography. This can be explained by the effect of exercise that causes more stress on the already overloaded right ventricle inducing more dilatation. However, the fact that gated SPECT studies are performed 30 minutes after tracer injection, therefore, right ventricular stress should have waned at the time of gating. Another reasonable explanation could be the possibility that gated SPECT is more sensitive for right ventricular overload detection than echocardiography [20].

In our study, we demonstrated that apart from right ventricular hypertrophy, flattening of the interventricular septum is a feature of significant pulmonary artery hypertension, which also can be detected during myocardial perfusion SPECT studies. The phenomenon of "D shaped left ventricle", ie flattening of the interventricular septum during both systole and diastole in right ventricular pressure overload or only during diastole in right ventricular volume overload has been previously reported during echocardiographic studies [21, 22].

However, the analogous phenomenon on nuclear imaging was recently described by Movahed et al, who were the first to use the terminology "interventricular septal flattening" and "D-shape left ventricle" in gated SPECT images [23]. Then, Maedar et al described a case of 49 year old man with a history of sarcoidosis associated with severe pulmonary hypertension and right ventricular systolic pressure of $65 \mathrm{~mm} \mathrm{Hg}$, who was referred for myocardial perfusion imaging because of 
preoperative workup [planed lung transplant], 99mTc sestamibi SPECT revealed markedly dilated and hypertrophied right ventricle with flattened interventricular septum during both systole and diastole, thus resulting in the picture of "D-shaped left ventricle" [24].

In our study, septal fattening was detected in 56/68 patients $(82 \%)$. Movahed et al detected this phenomenon in all his studied patients. The difference in results can be explained by his small sample size as he studied only 8 patients in comparison to 68 patients examined in our study. The D shaped left ventricle and hypertrophied, dilated right ventricle in cardiac SPECT imaging has been also reported by Shih et al in a patient with chronic obstructive pulmonary disease and pulmonary hypertension confirmed during autopsy [25].

In our study septal flattening was an indirect predictor for pulmonary hypertension and right ventricular overload. This was confirmed by the significant correlation between septal flattening in gated SPECT and pulmonary artery pressure, pulmonary artery diameter and RV tracer uptake compared to patients without septal flattening.

The previous phenomenon can be explained by the surprising finding of abnormal tracer uptake in the septum during rest, thus mimicking a fixed defect most likely consistent with a scar. This finding is not entirely clear, although data from a canine model suggest that acute right ventricular pressure overload [induced by pulmonary artery banding] significantly compromises septal coronary blood flow [26], which led to the speculation that anginalike chest pain in patients with pulmonary hypertension but normal epicardial coronary arteries might reflect ischemia due to septal compression [26]. The septal hypoperfusion was inconsistent finding in our study as among all cases that showed septal flattening only 15 patients (22\%) showed septal perfusion defect.The fact that left ventricular diastolic dysfunction, as assessed by echocardiography, correlated significantly with septal flattening denotes the importance of this finding as indicator for the hemodynamic performance of the left ventricle.

Based on our observations, physicians should give more attention to the shape of the interventricular septum which could help detect pulmonary arterial hypertension or right ventricular overload. The discovery of interventricular septal flattening [ $D$ shaped left ventricle] should be included in myocardial perfusion reports similar to the echocardiographic report of right ventricular overload. This was also reported recently by Murarka and Movahed, who stressed on inclusion of the high right ventricular tracer uptake, large right ventricular cavity, Movahed's sign or D shaped left ventricle on gated SPECT imaging if present as an indication of abnormal right ventricle [27].

\section{Conclusion}

Flattening of the interventricular septum [D-shape left ventricle] in gated SPECT imaging is a sign of RV overload and correlates with the same phenomenon described on echocardiography. Reporting of the interventricular septal flattening during the interpretation of gated SPECT studies, if present should be considered as it raises the attention that these patients are suspected to have RV overload.

\section{References}

1. Matthews JC, Dardas TF, Dorsch MP, Aaronson KD. Right-sided heart failure: diagnosis and treatment strategies. Curr Treat Options Cardiovasc Med 10:329-341; 2008.

2. Voekl NF, Quaife RA, Leinw and LA, Barst RJ, McGoon MD, Meldrum D Retal. Right ventricular function and failure report of a National Heart, Lung, and Blood Institute and working group on 
cellular and molecular mechanisms of right heart failure. Circulation 114:1883-1891; 2006

3. Kondo C. Myocardial perfusion imaging in pediatric cardiology. Ann Nucl Med 18:551-561; 2004.

4. Akiba T, Yoshikawa M, Otaki S, Nakasato M, Suzuki H, Sato S, Sato T. Estimation of right ventricular pressure in children by thallium-201 myocardial imaging using single photon emission computed tomography. Am J Cardiol 69:673-676; 1992.

5. Cohen HA, Baird MG, Rouleau JR, Fuhrmann CF, Bailey IK, Summer WR, Strauss HW, Pitt B. Thallium 201 myocardial imaging in patients with pulmonary hypertension. Circulation. 54: 790-795; 1976.

6. Nakajima K, Taki J, Ohno T, Taniguchi M, Taniguchi M, Bunko H, Hisada K. Assessment of right ventricular overload by a thallium-201 SPECT study in children with congenital heart disease. J Nucl Med. 32:2215-20; 1991.

7. Khaja F, Alam M, Goldstein S, Anbe DT, Marks DS. Diagnostic value of visualization of the right ventricle using thallium-201 myocardial imaging. Circulation. 59:182-8; 1979.

8. Eguchi M, Tsuchihashi K, Nakata T, Hashimoto A, Shimamoto K. Right ventricular abnormalities assessed by myocardial single photon emission computed tomography using technetium-99m sestamibi/tetrofosmin in right ventricle-originated ventricular tachyarrhythmias. J Am Col Cardiol. 36:1767-73; 2000.

9. Feneley M, Gavaghan T. Paradoxical and pseudoparadoxical interventricular septal motion in patients with right ventricular volume overload. Circulation. 74:230-8; 1986.

10. Weyman AE, Wann S, Feigenbaum H, Dillon JC. Mechanism of abnormal septal motion in patients with right ventricular volume overload: a cross-sectional echocardiographic study. Circulation. 54:179-86; 1976.
11. Russel R, Nuclear cardiology case of the month, March Am College of Cardiology web site 2004.

12. Arora R, Zhao QH, Guguchev PA, Wexler JP, Travin MI. Identification of severe right ventricular dysfunction and pressure overload by stress radionuclide myocardial perfusion SPECT imaging with gating. J Nucl Cardiol. 6:375-376; 1999.

13. Otani H, Kagaya Y, Yamane Y, Chida M, Ito K, Namiuchi S, Shiba N, Koseki Y, Ninomiya M, Ikeda J, Saito H, Maruoka S, Fujiwara T, Ido T, Ishide N, Shirato K. Long-term right ventricular volume overload increases myocardial fluorodeoxyglucose uptake in the interventricular septum in patients with atrial septal defect. Circulation. 101:1686-1692; 2000.

14. ACC/AHA/ASNC guidelines for the clinical use of cardiac radionuclide imaging-executive summary: a report of the American College of Cardiology/American Heart Association Task Force on Practice Guidelines [ACC/AHA/ASNC] Committee to Revise the 1995 Guidelines for the Clinical Use of Cardiac Radionuclide Imaging]. J Am Col Cardiol. 42:1318-1333; 2003.

15. Raymond RJ, Hinderliter AL, Willis PW, Ralph D, Caldwell EJ, Williams W, Ettinger NA, Hill NS, Summer WR, Boisblanc B, Schwartz T, Koch G, Clayton LM, Jöbsis MM, Crow JW, Long W. Echocardiographic predictors of adverse outcomes in primary pulmonary hypertension. $\mathbf{J}$ Am Coll Cardiol. 39:1214-9; 2002.

16.McLaughlin V, Presberg K, Doyle R, Abman SH, McCrory DC, Fortin T, Ahearn G. Prognosis of pulmonary arterial hypertension: ACCP evidence-based clinical practice guidelines. Chest. 126[suppl 1]:78S-92S; 2004;.

17.Brachman MB, Rozanski A, Charuzi Y, Maddahi J, Waxman AD, Berman DS. Thallium201 stress redistribution abnormalities of the right ventricle: A manifestation of proximal right coronary artery stenosis. American heart journal $3: 288-291 ; 1981$.

18.Wackers FJ, Klay JW, Laks H, Schnitzer J, Zaret BL, Geha AS. Pathophysiologic correlates of 
right ventricular thallium-201 uptake in a canine model. Circulation. 64:1256-1264; 1981.

19.Higgins JP. Increased right ventricular uptake on stress SPECT myocardial perfusion images in a patient with severe coronary artery disease. Nucl Cardiol J 13:725-727; 2006.

20.Aepfelbacher FC, Yeon SB, Ho KK, Parker JA, Danias PG. ECG- gated 99mTc single-photon emission CT for assessment of right ventricular structure and function: is the information provided similar to echocardiography? Chest. 124:227-232; 2003.

21.Bossone E, Duong-Wagner TH, Paciocco G, Oral H, Ricciardi M, Bach DS, Rubenfire M, Armstrong WF. Echocardiographic features of primary pulmonary hypertension. J Am Soc Echocardiogr 12:655-662; 1999.

22.Stefanidnidis A, Koutroulis G, Gibbs JS, Nihoyannopoulos P. Role of echocardiography in the diagnosis and follow-up of patients with pulmonary arterial and chronic thromboembolic pulmonary hypertension. Hell J Cardiol. 45:48$58 ; 2004$.

23.Movahed MR, Hepner A, Lizotte P, Milne N. Flattening of the interventricular septum (D-shaped left ventricle) in addition to high right ventricular tracer uptake and increased right ventricular volume found on gated SPECT studies strongly correlated with right ventricular overload. J Nucl Cardiol 12:428-434; 2005.

24.Maedera MT, Stöcklib M, Zellweger MJ: Myocardial perfusion SPECT features of severe pulmonary artery hypertension. Kardiovaskuläre Medizin 10:113-114; 2007.

25.Shih W, Kousa K, Mitchell B, Huang W.

Permanently increased brightness of right ventricle (D-shaped left ventricle) on myocardial infusion imaging in a patient with chronic cor pulmonale: an autopsy correlation. J NuclCardiol 13:294-296; 2006.

26.Gibbons Kroeker CA, Adeeb S, Shrive NG, Tyberg JV. Compression induced by RV pressure overload decreases regional coronary blood flow in anaesthetized dogs. Am J Physiol Heart Circ Physiol. 290: 2432-2438; 2006.

27. Murarka $S$ and Movahed MR. Review of Movahed's sign (D shaped left ventricle seen on gated SPECT) suggestive of right ventricular overload. Int J Cardiovasc Imaging 26:553-557; 2010. 